\title{
Cenurose em ovinos no sul do Brasil: 16 casos
}

\author{
Coenurosis of sheep in southern Brazil: 16 cases
}

\section{Daniel Ricardo Rissi ${ }^{\mathrm{I}}$ Raquel Rubia Rech ${ }^{\mathrm{I}}$ Felipe Pierezan $^{\mathrm{I}}$ Adriane Loy Gabriel ${ }^{\mathrm{I}}$ Maria Elisa Trost ${ }^{\mathrm{I}}$ Claudio Severo Lombardo de Barros ${ }^{\mathrm{II}}$}

\section{RESUMO}

Neste trabalho são descritos casos de doença neurológica causada por Coenurus cerebralis em 16 ovinos provenientes de nove propriedades rurais do Rio Grande do Sul. Os casos ocorreram entre janeiro de 1990 e dezembro de 2006. A evolução clínica variou de 30-90 dias e os ovinos afetados apresentavam depressão (9/16), isolamento do rebanho (8/16), andar cambaleante (7/16), cegueira (4/16), desvio da cabeça (3/16), incoordenação (3/16), movimentos de pedalagem (2/16), quedas (2/16), andar em círculos, deficiência proprioceptiva nos membros torácicos e pélvicos, estrabismo, midríase, opistótono, tremores e rigidez dos membros (1/16 cada). Os achados macroscópicos foram restritos ao sistema nervoso central e caracterizados por cistos de 2 a $9 \mathrm{~cm}$ de diâmetro preenchidos por líquido translúcido e revestidos por fina membrana. Na parte interna da membrana, havia numerosas estruturas levemente alongadas e brancas de aproximadamente $1 \mathrm{~mm}$ de diâmetro (escólices). Na maioria dos ovinos, os cistos eram localizados no telencéfalo (12/16); em três, os cistos estavam no cerebelo e em um ovino havia um cisto no cerebelo e um na medula espinhal. Em todos os casos havia acentuada compressão e deslocamento do tecido nervoso adjacente aos cistos. Histologicamente, os cistos parasitários eram formados por dupla membrana fracamente eosinofílica da qual evaginavam múltiplos escólices esféricos acelomados. Adjacente à parede da vesícula eram observadas sucessivas camadas compostas por uma zona de necrose $e$ mineralização, circundadas por infiltrado inflamatório composto por macrófagos epitelióides e células gigantes multinucleadas, com uma cápsula externa de tecido fibrovascular e infiltrado inflamatório linfoistioplasmocitário perivascular. Adicionalmente, havia compressão e atrofia das substâncias branca e cinzenta adjacentes. O diagnóstico de cenurose foi realizado com base nos achados epidemiológicos, clínicos e macroscópicos, e confirmado pela histopatologia.
Palavras-chave: Coenurus cerebralis, Taenia multiceps, Multiceps multiceps, neuropatologia.

\section{ABSTRACT}

Sixteen cases of neurologic disease caused by Coenurus cerebralis occurring in sheep from nine farms in Rio Grande do Sul, Brazil, from January 1990 to December 2006, are described. Clinical courses varied from 30 to 90 days and affected sheep developed depression (9/16), isolation from the herd (8/16), staggering (7/16), blindness (4/16), head tilt (3/ 16), incoordination (3/16), paddling (2/16), falls (2/16), circling, proprioceptive deficits in fore and hindlimbs, strabismus, mydriasis, opisthotonus, trembling and rigidity of the limbs (1/16 each one). Macroscopic findings were restricted to central nervous system and consisted of 2 to $9 \mathrm{~cm}$ fluid filled cysts with numerous slightly elongated $1 \mathrm{~mm}$ white scolices attached to the inner wall surface of the capsule. Cysts were located in the telencephalon (12/16); in the cerebellum (3 sheep); and in the cerebellum and spinal cord (1 sheep). All cases showed severe compression and displacement of the adjacent nervous tissue. Histologically, the cyst walls were characterized by a thin walled eosinophilic vesicle in which evaginated multiple spherical acelomated scolices. The cyst wall was surrounded by successive layers consisting of an internal necrotic and mineralized band, a layer of epithelioid macrophages with abundant number of multinucleated giant cell and an external fibrovascular capsule with perivascular lymphohistioplasmacytic infiltrate. Adjacent white and gray matter were compressed and atrophied. The diagnosis was based on epidemiologic, clinical and pathologic findings and confirmed by histopathology.

Key words: Coenurus cerebralis, Taenia multiceps, Multiceps multiceps, neuropathology.

'Programa de Pós-graduação em Medicina Veterinária, área de concentração em Patologia Veterinária, Universidade Federal de Santa Maria (UFSM), Santa Maria, RS, Brasil.

"Laboratório de Patologia Veterinária, Departamento de Patologia, UFSM, 97105-900, Santa Maria, RS, Brasil. E-mail: claudioslbarros@uol.com.br. Autor para correspondência. 


\section{INTRODUÇÃO}

A cenurose é uma doença parasitária cosmopolita e comum em ovinos (SHARMA \& CHAUHAN, 2006) causada pela forma larval de Taenia (Multiceps) multiceps, denominada de Coenurus cerebralis (INNES \& SAUNDERS, 1962). A fase adulta do parasita ocorre no intestino delgado de canídeos domésticos e selvagens, que são os hospedeiros definitivos (HD). O período pré-patente de $\boldsymbol{T}$. multiceps é de aproximadamente 40 dias e os ovos contendo as oncosferas são liberados nas fezes do HD infestado e podem permanecer no ambiente por aproximadamente um mês (SCALA \& VARCASIA, 2006). Após a ingestão acidental pelo hospedeiro intermediário (HI), principalmente ruminantes, as oncosferas são liberadas dos ovos, penetram a mucosa intestinal e, pela circulação sanguínea ou linfática, invadem o sistema nervoso central (SNC), onde desenvolverão a forma larval e o cisto. O ciclo se completa quando o HD ingere o cisto contido em material infestado do HI. Os HI mais freqüentemente afetados pela cenurose são os ovinos (INNES \& SAUNDERS, 1962); raramente bovinos são infestados (FERREIRA et al., 1992), caprinos (RAZIG \& MAGZOUB, 1973) e outras espécies (INNES \& SAUNDERS, 1962). Casos de cenurose em seres humanos são raros e causados por T. serialis. Indivíduos afetados normalmente desenvolvem cistos no SNC ou nos tecidos subcutâneo e muscular, e se infestam pelo contato com fezes de cães contaminados. Coelhos, lebres e roedores desenvolvem cistos de $\boldsymbol{T}$. serialis nos tecidos subcutâneo e muscular (ING et al., 1998).

São reconhecidas duas formas de cenurose em ovinos: 1) a forma aguda, que ocorre cerca de um mês após a invasão larval no SNC e 2) a forma crônica, associada ao desenvolvimento de sinais clínicos secundários à ocupação de espaço pelo cisto parasitário (INNES \& SAUNDERS, 1962), que se desenvolve de dois a quatro meses após a infestação. $\mathrm{Na}$ forma aguda, há ataxia, tremores musculares, hiperestesia, hipermetria e decúbito (DOHERTY et al., 1989). A forma crônica é a mais comum e os principais sinais clínicos são isolamento do rebanho, depressão, cegueira, andar em círculos, desvio da cabeça e incoordenação (TIRGARI et al., 1987; ACHENEF et al., 1999; OZMEN et al., 2005).

Apesar de ser uma doença comum de ovinos em várias regiões do mundo, a cenurose não tem sido detalhadamente documentada no Brasil, apesar de sua conhecida existência no país. O objetivo deste trabalho foi descrever a epidemiologia, os sinais clínicos e os achados de necropsia e histológicos de 16 casos de cenurose (forma crônica) em ovinos, diagnosticados no Laboratório de Patologia Veterinária (LPV) da Universidade Federal de Santa Maria (UFSM) entre 1990 e 2006.

\section{MATERIAL E MÉTODOS}

Foi realizado um estudo de 16 casos de cenurose em ovinos provenientes de nove propriedades rurais do Rio Grande do Sul localizadas na área de abrangência do LPV-UFSM entre os anos de 1990 e 2006. Os dados epidemiológicos e clínicos foram obtidos junto aos proprietários ou veterinários encarregados dos casos. Os ovinos afetados foram identificados por numeração de 1 a 16 . Fragmentos de vários órgãos foram coletados, incluindo os encéfalos inteiros e o monobloco composto pelo gânglio de Gasser, rete mirabile carotídea e hipófise (GRH), e fixados em formol a 10\%. A descrição macroscópica foi realizada por cortes seriados de $1 \mathrm{~cm}$ dos encéfalos. Após esse procedimento, todo o material foi processado rotineiramente para histologia e corado pela técnica de hematoxilina-eosina (HE).

\section{RESULTADOS}

No período avaliado foram examinados 1.015 ovinos no LPV-UFSM (396 necropsias e 619 exames histopatológicos), dos quais 46 (4,5\%) apresentaram doença neurológica, destes, 16 (34,7\%) tiveram diagnóstico de cenurose. Os dados epidemiológicos das nove propriedades que tiveram o rebanho afetado estão resumidos na tabela 1. Os sinais clínicos eram semelhantes em todos os casos e incluíam, em ordem decrescente de freqüência, depressão (9/16), isolamento do rebanho (8/16), andar cambaleante (7/ $16)$, cegueira (4/16), desvio da cabeça (3/16), incoordenação (3/16), movimentos de pedalagem (2/ 16), quedas (2/16), andar em círculos, deficiência proprioceptiva nos membros torácicos e pélvicos, estrabismo, midríase, opistótono, tremores e rigidez dos membros (1/16 cada). A evolução clínica variou de 3090 dias. Em duas propriedades, havia relato de que os ovinos afetados mantiveram o apetite mesmo doentes. Em uma propriedade houve confirmação de que os cães eram alimentados com restos de carcaça frescas de ovinos e em outra havia instalação própria para o abate de ovinos.

Os achados macroscópicos foram restritos ao SNC e eram observados achatamentos das circunvoluções do telencéfalo, herniação subtentorial ou cerebelar (Figura 1A), com atrofia do parênquima adjacente e hidrocefalia nos ventrículos laterais (Figura 
Tabela 1 - Dados epidemiológicos dos 16 casos de cenurose em ovinos no Rio Grande do Sul entre 1990 e 2006.

\begin{tabular}{|c|c|c|c|c|c|c|c|c|c|}
\hline $\mathrm{P}^{\mathrm{a}}$ & Município & Época & Sexo & $\begin{array}{l}\text { Idade } \\
\text { (meses) }\end{array}$ & Raça & Morte & $\begin{array}{l}\text { Ovinos sob } \\
\text { risco }\end{array}$ & $\begin{array}{l}\text { Ovinos } \\
\text { afetados }\end{array}$ & $\begin{array}{l}\text { Ovinos } \\
\text { mortos }\end{array}$ \\
\hline 1 & São Sepé & $\mathrm{mar} / 1991$ & $\mathrm{M}^{\mathrm{b}}$ & $\mathrm{ni}^{\mathrm{c}}$ & Ile de France & eut $^{\mathrm{d}}$ & ni & 10 & 10 \\
\hline 2 & São Vicente do Sul & abr/1991 & $\mathrm{F}^{\mathrm{e}}$ & 6 & mista & ni & ni & 10 & 10 \\
\hline 3 & Restinga Seca & fev/1993 & M & 30 & mista & eut & ni & ni & ni \\
\hline 4 & Dom Pedrito & $\begin{array}{l}\text { out/1999- } \\
\text { jun/2006 }\end{array}$ & $\mathrm{MF}^{\mathrm{f}}$ & 18 & Corriedale & eut & 250 & 7 & 7 \\
\hline 5 & São Borja & out/2001 & $\mathrm{F}$ & 10 & $\begin{array}{l}\text { Hampshire } \\
\text { Down }\end{array}$ & eut & 955 & 18 & 18 \\
\hline 6 & Quaraí & mar/2005 & $\mathrm{F}$ & 18 & Ile de France & eut & ni & ni & ni \\
\hline 7 & Santiago & set/2006 & $\mathrm{F}$ & 12 & mista & $\mathrm{esp}^{\mathrm{g}}$ & 420 & 1 & 1 \\
\hline 8 & Dom Pedrito & nov/2006 & M & 24 & Corriedale & eut & 1000 & 1 & 1 \\
\hline 9 & Santa Maria & dez/2006 & F & 5 & mista & eut & 130 & 13 & 13 \\
\hline
\end{tabular}

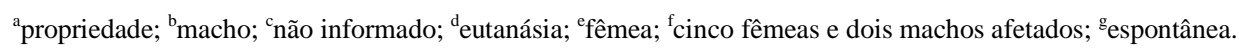

1B). Os cistos variavam de 2-9cm de diâmetro e eram revestidos por uma fina cápsula transparente. Ao corte, esses cistos eram repletos por líquido translúcido e apresentavam numerosas estruturas brancas levemente alongadas de aproximadamente $1 \mathrm{~mm}$ (escólices) aderidas à face interna da cápsula (Figura 1C). Em todos os casos os cistos causavam compressão e deslocamento do parênquima nervoso adjacente. Em 15 ovinos havia um único cisto ou vários que coalesciam, localizados no telencéfalo (12 ovinos) ou no cerebelo (três ovinos). Em um caso havia dois cistos em locais diferentes, um no cerebelo e um na medula espinhal. Em um ovino (Ovino 15) havia diminuição da espessura e amolecimento dos ossos frontais do crânio, evidenciada pela palpação.

Histologicamente os cistos eram compostos por duas membranas fracamente eosinofílicas (externa e interna), com dilatações da interna, de onde evaginavam numerosos escólices esféricos de $\boldsymbol{C}$. cerebralis de aproximadamente $1 \mathrm{~mm}$ de diâmetro (Figura 1D). Os escólices apresentavam o parênquima envolto por tegumento, eram acelomados e desprovidos de trato digestivo. Foram observadas numerosas e diminutas estruturas basofílicas ovais distribuídas pelo parênquima do parasita (corpos calcáreos). Em algumas seções verificaram-se estruturas circulares compostas por músculos com fibras em arranjo radial (aparelho sugador) ou rostelo com ganchos no pólo anterior do escólex (Figura 1E), que eram birrefringentes sob luz polarizada. Adjacente à parede do cisto eram observadas áreas focalmente extensas de necrose e infiltrado composto de macrófagos epitelióides e células gigantes multinucleadas tipos Langhans e corpo estranho, com áreas de deposição de material granular amorfo basofílico (mineralização). Nas áreas perilesionais, foram observados infiltrado linfoistioplasmocitário perivascular leve a acentuado em meio a fibroblastos e vasos (Figura 1F), compressão e edema do parênquima adjacente. Adicionalmente, no Ovino 5 havia infiltração perilesional por células Gitter (malacia), e no Ovino 10, extenso infiltrado linfoplasmocitário e focos de gliose desde os ventrículos laterais até o aqueduto mesencefálico (ventriculite). Ocasionalmente, foram observados gliose e manguitos perivasculares linfoistiocitários leves ou moderados em áreas distantes do cisto.

\section{DISCUSSÃO}

O diagnóstico de cenurose foi realizado com base nos achados epidemiológicos, clínicos e de necropsia e confirmado pelo exame histopatológico. Foram afetados ovinos de cinco a 30 meses de idade (média de 13,6), de várias raças e ambos os sexos, e a doença não apresentou característica sazonal. De um total de 2.755 ovinos sob risco (em cinco das nove propriedades onde essa informação estava disponível), 40 foram afetados, resultando em um índice de morbidade de $1,45 \%$. Como na maioria das propriedades os animais afetados foram submetidos à eutanásia, não foi possível calcular os índices de mortalidade e letalidade. Esses dados são escassos na literatura, porém, quando citados, são semelhantes aos encontrados neste trabalho (SHARMA \& CHAUHAN, 2006). Os 16 casos de cenurose totalizaram aproximadamente $35 \%$ das doenças do SNC de ovinos examinados durante os 16 anos abrangidos pelo estudo. Essa foi a doença neurológica de ovinos mais prevalente na área de influência do LPV-UFSM durante esse período. É interessante notar que 11 dos 16 casos de cenurose (aproximadamente 68\%) foram 


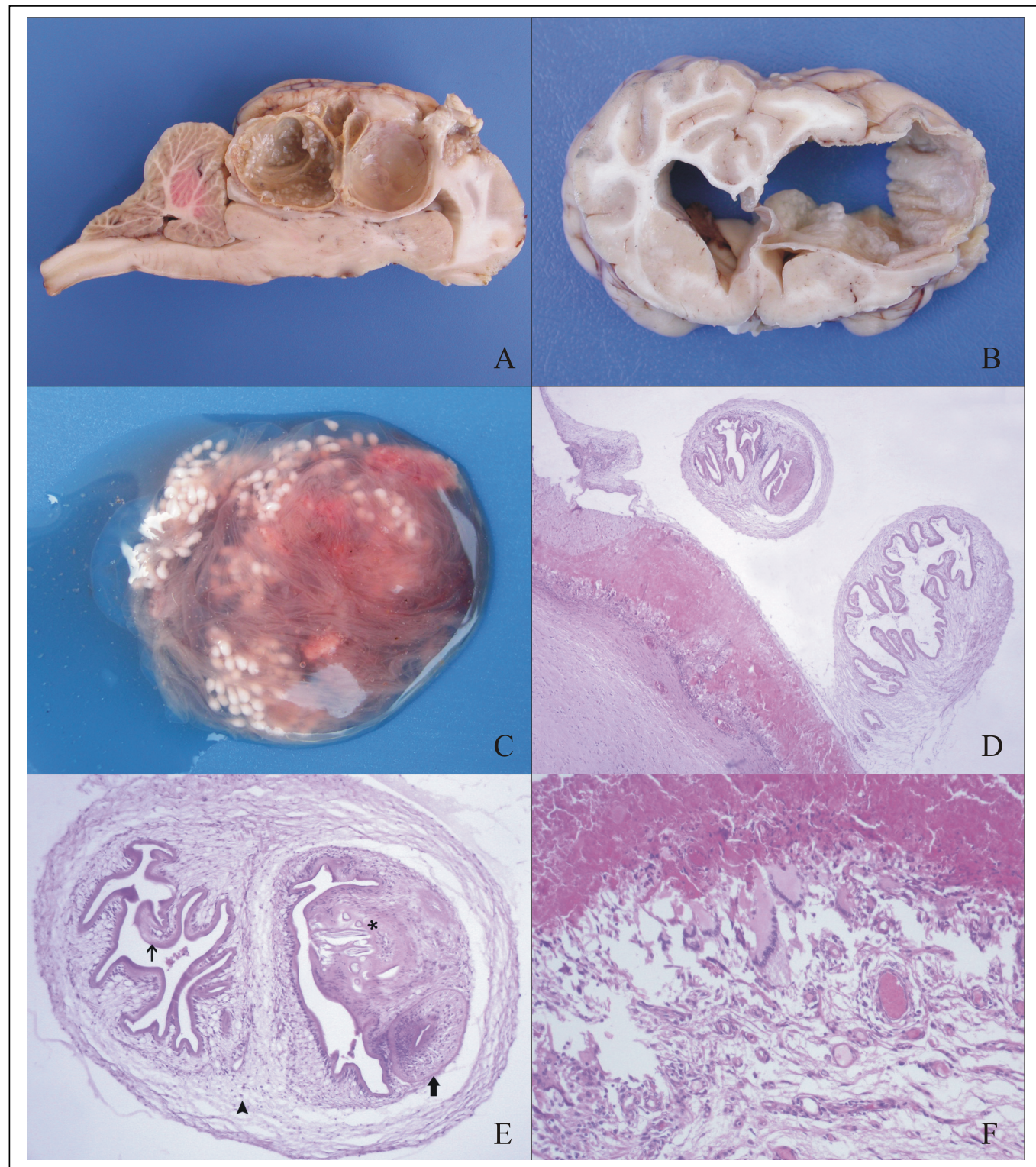

Figura 1 - Cenurose em ovinos no Sul do Brasil. A. Corte longitudinal do telencéfalo mostrando cistos coalescentes (Ovino 14). No interior do cisto caudal, há numerosos escólices aderidos à membrana interna. Observe a acentuada herniação cerebelar e compressão do tronco encefálico, diencéfalo e núcleos basais, com deslocamento cranial do ventrículo lateral. B. Corte transversal do encéfalo na altura dos núcleos basais (Ovino 15). Há assimetria acentuada causada por um cisto de $6 \mathrm{~cm}$ de diâmetro que distende o hemisfério telencefálico esquerdo. Há atrofia da corona radiata, desvio lateral do septo pelúcido, redução da luz do ventrículo lateral esquerdo e hidrocefalia no ventrículo lateral direito. C. Conteúdo do cisto parasitário composto por líquido translúcido envolto por uma fina membrana na qual estão aderidos numerosos escólices. D. Encéfalo (Ovino 15). Há dois escólices evaginados da membrana interna do cisto. Observe a reação tecidual adjacente, caracterizada por uma zona focalmente extensa de necrose circundada por infiltrado inflamatório. Hematoxilina-eosina. E. Escólex acelomado de Coenurus cerebralis (Ovino 16) caracterizado pela ausência de trato digestivo e numerosas e diminutas estruturas basofílicas ovais (corpos calcáreos) distribuídas aleatoriamente pelo parênquima (cabeça de seta). Observe a cutícula de revestimento (seta estreita), a estrutura circular composta por músculos com fibras em arranjo radial (aparelho sugador) (seta espessa) e parte do rostelo com ganchos (asterisco) no pólo anterior do escólex. Hematoxilina-eosina. G. Escólex de Coenurus cerebralis mostrando ganchos birrefringentes sob luz polarizada (Ovino 16). Hematoxilina-eosina. F. Encéfalo (Ovino 15). A reação adjacente à parede do cisto se caracteriza por uma área focalmente extensa de necrose circundada por macrófagos epitelióides e células gigantes multinucleadas e infiltrado inflamatório linfoistioplasmocitário perivascular em meio a fibroblastos e vasos. Hematoxilinaeosina. 
diagnosticados a partir de 2001 e essa concentração de diagnósticos coincide com o período de implantação do Programa Nacional de Controle da Raiva dos Herbívoros e outras Encefalopatias no LPV. Isso indica que houve um aumento no número de diagnósticos de doenças do SNC de ruminantes após o início da vigilância ativa por parte do programa.

O exame de palpação dos ossos do crânio foi realizado nos ovinos provenientes das propriedades quatro a 9. Não havia informações referentes a esse procedimento nos demais laudos examinados. A diminuição da espessura dos ossos frontais, decorrente da pressão causada pelo cisto, foi observada somente no Ovino 15, proveniente da Propriedade 8. Esse achado tem importância no diagnóstico clínico de cenurose, pois determina a exata localização do cisto (SKERRITT \& STALLBAUNER, 1984). Exames complementares, principalmente avaliação neurológica, devem ser realizados na ausência dessa lesão (TIRGARI et al., 1987).

O exame radiográfico é usado principalmente em casos onde há perspectivas de remoção cirúrgica, procedimento realizado quase exclusivamente em animais de alto valor zootécnico (TIRGARI et al., 1987). Exames clínicos e radiográficos não foram realizados nos casos deste estudo, pois os ovinos examinados já chegavam mortos ao laboratório ou somente material de necropsia era remetido. Cistos parasitários no SNC de ovinos são formados após a migração e o estabelecimento de $\boldsymbol{C}$. cerebralis no parênquima nervoso (INNES \& SAUNDERS, 1962). Nos casos descritos neste trabalho, o diagnóstico macroscópico de cenurose foi bastante específico, indicando que numa região endêmica para a doença o diagnóstico macroscópico durante a necropsia é bastante seguro e dá a oportunidade de o proprietário agir prontamente e ingressar com medidas de controle e prevenção adequadas para a doença.

As medidas de prevenção em áreas endêmicas para cenurose devem se basear na interrupção do ciclo do parasita, pelo não fornecimento de vísceras de ovinos ao HD. Adicionalmente, todos os cães residentes em uma propriedade rural devem ser vermifugados periodicamente. Medidas terapêuticas para ovinos afetados incluem a administração de fármacos antiparasitários (GHAZAEI, 2006) e tratamento cirúrgico (SKERRITT \& STALLBAUMER, 1984), que apesar de eficiente tem seu uso limitado economicamente (GHAZAEI, 2006). Fármacos como albendazole, praziquantel e febendazole têm demonstrado efeito antiparasitário sobre cistos de C. cerebralis em ovinos infectados experimentalmente (GHAZAEI, 2006). No entanto, alguns autores afirmam que o tratamento não é eficiente em casos em que já houve a formação do cisto (OZMEN et al., 2005). Apesar de muitos veterinários relatarem o uso de vermífugos nos cães nos locais onde a doença ocorria, muitas vezes não houve resultados satisfatórios e foram informados novos casos da doença. Um aspecto importante da cenurose é a existência de ovinos que desenvolvem cistos pequenos e não apresentam sinais clínicos (ACHENEF et al., 1999). Esses indivíduos podem desempenhar importante papel epidemiológico, pois provavelmente não serão detectados como infestados e atuarão no fechamento do ciclo parasitário, contribuindo para a manutenção da doença em uma área. Apesar de somente em uma das nove propriedades deste estudo haver informação de que os cães eram alimentados com vísceras de ovinos, é provável que essa informação tenha sido ignorada ou desconhecida nas outras propriedades, pois não há outra forma de ocorrência do ciclo parasitário completo senão pela ingestão, pelos ovinos, das oncosferas liberadas nas fezes de cães infestados por T. multiceps. Na Propriedade 8 havia uma instalação própria para o abate de ovinos, caracterizada por um pequeno cercado coberto, na qual os cães não tinham acesso. Nessa propriedade os cães eram periodicamente everminados e a infestação de um ovino foi atribuída à introdução de cães errantes ou que acompanhavam funcionários temporários que eram periodicamente contratados pelo proprietário.

Todos os casos descritos neste trabalho são da forma crônica de cenurose, que é a forma mais comum da doença (DOHERTY et al., 1989). Os sinais clínicos mais freqüentemente observados ou relatados consistiam de depressão, isolamento do rebanho, andar cambaleante, desvio lateral da cabeça, cegueira e incoordenação. Esses sinais são semelhantes aos descritos por outros autores (DE LAHUNTA, 1983; OZMEN et al., 2005). Na maioria dos casos (12/16) os cistos eram localizados no telencéfalo; em três casos, no cerebelo e em um caso (Ovino 2), na medula espinhal cervical e no cerebelo. $O$ telencéfalo é descrito como o principal sítio de implantação do cisto em casos de cenurose (SHARMA \& CHAUHAN, 2006) e lesões nesse local são evidenciadas principalmente por alterações no comportamento ou estado mental, convulsões e deficiência visual e postural. Em casos de lesões focais, os animais podem andar em círculos e apresentar desvio da cabeça. Nesses casos, alguns autores relatam que esses sinais são, na maioria das vezes, contralaterais à lesão (DE LAHUNTA, 1983). Nos casos de cenurose aqui descritos não foi observada relação entre esses parâmetros e isso provavelmente seja devido ao fato de os sinais não 
estarem relacionados somente à ocupação de espaço pelo cisto, mas também à compressão e ao deslocamento das estruturas adjacentes contralaterais. Em cinco casos, os cistos ocupavam ambos os hemisférios telencefálicos, o que provavelmente também contribuiu para a ausência de relação entre os sinais clínicos e o lado da lesão (ACHENEF et al., 1999).

Em 15 casos deste estudo os cistos estavam localizados no encéfalo e somente em um ovino (Ovino 2) foi observado cisto na medula espinhal. Sinais clínicos relacionados com cistos na medula espinhal incluem debilidade, alterações posturais e incoordenação (BUSSELL et al., 1997). No entanto, neste estudo, a incoordenação apresentada por dois ovinos (Ovinos 2 e 3 ) foi relacionada ao desenvolvimento de cistos cerebelares (OZMEN et al., 2005). Os sinais de incoordenação observados no Ovino 9, que não apresentava cisto no cerebelo, possivelmente estavam relacionados ao envolvimento cerebelar secundário decorrente do cisto no telencéfalo.

Histologicamente, as características de escólices acelomados enquadram o parasita nas classes Cestoda ou Trematoda. A diferenciação é realizada com base na ausência de trato digestivo e presença de corpos calcáreos no parênquima, achado característico dos cestódeos. Adicionalmente, os ganchos classificam o parasita como membro da família Taeniidae. Existem vários tipos de cistos larvais de cestódeos. A diferenciação entre cistos de Coenurus spp. e outros cistos é realizada com base na localização e na presença de múltiplos escólices, característicos das larvas de $\boldsymbol{T}$. multiceps (GARDINER \& POYTON, 1999).

\section{CONCLUSÕES}

Apesar de ser uma doença bem reconhecida, o presente trabalho demonstra que a cenurose continua ocorrendo de forma endêmica na área de abrangência do LPV-UFSM. O diagnóstico diferencial das doenças do SNC de ovinos se tornou foco de maior interesse técnico diante do aumento de diagnósticos de casos autóctones de scrapie no rebanho ovino brasileiro. O sistema de vigilância epidemiológica ativa e criteriosa que vem sendo desenvolvido em vários laboratórios do país permitirá o conhecimento das doenças neurológicas de ovinos em uma determinada região, o que permitirá que o produtor reconheça as doenças de seu rebanho e que o veterinário direcione o diagnóstico mais precisamente.

\section{APRESENTAÇÃO}

Parte da tese de Doutorado do primeiro autor (bolsista do CNPq), Programa de Pós-graduação em Medicina
Veterinária da Universidade Federal de Santa Maria, área de concentração em Patologia Veterinária.

\section{REFERÊNCIAS}

ACHENEF, M. et al. Coenurus cerebralis infection in Ethiopian Highland sheep: Incidence and observations on pathogenesis and clinical signs. Tropical Animal Health and Production, v.31, n.1, p.15-24, 1999.

BUSSELL, K.M. et al. Posterior paralysis in a lamb caused by Coenurus cerebralis cyst in the lumbar spinal cord. Veterinary Record, v.140, n.21, p.560, 1997.

DE LAHUNTA, A. Veterinary neuroanatomy and clinical neurology. Philadelphia: Saunders, 1983. 471p.

DOHERTY, M.L. et al. Outbreak of acute coenuriasis in adult sheep in Ireland. Veterinary Record, v.125, n.8, p.185, 1989.

FERREIRA, J.L. et al. Coenurose em bovinos no Rio Grande do Sul. Revista Brasileira de Parasitologia Veterinária, v.1, n.2, p.113-116, 1992.

GARDINER, C.H.; POYNTON, S.L. An atlas of metazoan parasites in animal tissues. Washington, D.C.: Armed Forces Institute of Pathology, 1999. 64p.

GHAZAEI, C. Evaluation therapeutic effects of antihelminthic agents albendazole, fenbendazole and praziquantel against coenurosis in sheep. Small Ruminant Research, v.71, p.4851, 2006.

ING, M.B. et al. Human coenurosis in North America: case reports and review. Clinical Infectious Diseases, v.27, n.3, p.519-523, 1998.

INNES, J.R.M.; SAUNDERS, L.Z. Helmintic infections. In: Comparative neuropathology. New York: Academic, 1962. Cap.13, p.531-569.

OZMEN, O. et al. Clinicopathologic observations on Coenurus cerebralis in naturally infected sheep. Schweizer Archiv fur Tierheilkunde, v.147, n.3, p.129-134, 2005.

RAZIG, S.A.; MAGZOUB, M. Goat infected with Coenurus cerebralis - clinical manifestations. Tropical Animal Health and Production, v.5, n.4, p.278-280, 1973.

SCALA, A.; VARCASIA, A. Updates on morphobiology, epidemiology and molecular characterization of coenurosis in sheep. Parassitologia, v.48, n.1-2, p.61-63, 2006.

SHARMA, D.K.; SHAUHAN, P.P.S. Coenurosis status in AfroAsian region: a review. Small Ruminant Research, v.64, n.3, p.197-202, 2006.

SKERRITT, G.C.; STALLBAUMER, M.F. Diagnosis and treatment of coenuriasis (gid) in sheep. Veterinary Record, v.115, n.16, p.399-403, 1984.

TIRGARI, M. et al. Clinical and radiographical diagnosis of coenurosis cerebralis in sheep and its surgical treatment. Veterinary Record, v.120, n.8A, p.173-178, 1987. 